\title{
Modeling an impact of road geometric design on vehicle energy consumption
}

\author{
Blaž Luin ${ }^{1, *}$, Stojan Petelin ${ }^{1}$, and Fouad Al-Mansour ${ }^{2}$ \\ ${ }^{1}$ Faculty of Maritime Studies and Transportation, University of Ljubljana, Slovenia \\ ${ }^{2}$ Jozef Stefan Institute, Jamova cesta 39, 1000 Ljubljana, Slovenia
}

\begin{abstract}
Some roads connect traffic origins and destinations directly, some use winding, indirect routes. Indirect connections result in longer distances driven and increased fuel consumption. A similar effect is observed on congested roads and mountain roads with many changes in altitude. Therefore a framework to assess road networks based on energy consumption is proposed. It has been shown that road geometry has significant impact on overall traffic energy consumption and emissions. The methodology presented in the paper analyzes impact of traffic volume, shares of vehicle classes, road network configuration on the energy used by the vehicles. It can be used to optimize energy consumption with efficient traffic management and to choose optimum new road in the design phase. This is especially important as the energy consumed by the vehicles shortly after construction supersedes the energy spent for the road construction.
\end{abstract}

\section{Introduction}

The European Union puts a lot of effort on policies for energy efficiency and to decrease emissions in transport [1]. Transport sector is contributing nearly a third of $\mathrm{CO}_{2}$ emissions and energy consumption within the EU [2]. Most efforts to combat this problem are directed towards traffic mode shift, use of energy-efficient vehicles and alternative fuels [3]. As a result there was a decline of overall emissions by 3\% in 2012 and by 2014 average light vehicle emissions were below the targets set for 2015. These values were obtained in part as the EU requires member states to record data on registering motor vehicles [4]. Similar policies are being practiced elsewhere in the world, such as in the USA and China $[5,6]$. Such transport policies also focus on limiting road traffic in cities, increasing use of public transport and on shifting from road to other modes of transport. Such approaches work well in densely populated areas, but in sparsely populated areas road traffic is still, necessarily, the transportation mode of choice. An example of a study of reducing emissions in a densely populated area is the article [7], where a case study from London is described. An alternative to such approaches can be better traffic management that could result in less congestion and lower emissions.

When roads are preferred option and shift to other modes is difficult to achieve, more focus should be put on relation between greenhouse emissions and road network

\footnotetext{
*Corresponding author: blaz.luin@fpp.uni-lj.si
} 
configuration including traffic management. Traffic simulation and emissions models are a tools that should be applied to optimize the traffic network.

Traffic microsimulation models need to be coupled with emission models in order to obtain individual and aggregated vehicle emissions. Vehicle emission models can be divided into microscopic and macroscopic. Macroscopic emission models are used to estimate emissions based on traffic volume and average speed, ignoring instantaneous accelerations. More detailed are the microscopic emission models that rely on inputs such as speed, acceleration, vehicle weight and road grade.

Regardless if the model is microscopic or macroscopic, most models provide no direct physical model of fuel consumption, rather tables or functions that are based on statistical analysis of different variables that have an impact on emissions $[8,9]$. One example of a macroscopic model is the ARTEMIS study that involves $\mathrm{CO} 2$ and NOX emissions dependant on vehicle speed and driving cycles [10, 11]. A statistical analysis of the dependence of truck fuel consumption on speed and road grade was conducted in an experimental study by [12] conducted on highways in realistic traffic conditions. Fuel volume flow was measured using the vehicles' CAN (Controller Area Network) bus interface. Such results can be used for comparative purposes and for model tuning but not for direct estimation of instantaneous fuel consumption for different types of vehicles that is required for microsimulation. For general energy demand forecasting models with lower level of detail are used. In [13], where a long-term forecasting was simulated, a straight-forward model based on mileage travelled and average fuel economy was applied.

Notable microsimulation models are Versit+, PHEM, CMEM and VT-Micro. Versit+ is a model that is based on a vehicle type, velocity and acceleration [14] that was developed by the TNO from Netherlands. It has interface with AIMSUN traffic microsimulation software. The AIMSUN is based on the Gipps model therefore velocity must be differentiated to obtain acceleration [15]. PHEM is an emissions model that was developed by the University of Graz and has interface for the SUMO microscopic traffic simulator [16-18]. CMEM and VT are models that were development in the USA. The CMEM was developed during the $90 \mathrm{~s}$ and was afterwards, while the VT (Virginia Tech) is a newer model. Both of them are based on velocity, acceleration and factors that depend on vehicle types.

Since new fuels and electric vehicles are becoming increasingly popular, calculating energy impact of traffic can be difficult. A lot more straight-forward approach would be to rely on the energy required by the vehicle directly. Among all approaches, the VSP (vehicle specific power) model was the only one that was directly based on power required by the vehicle $[19,20]$. Vehicle specific power is based on energy conversions, changes of potential and kinetic energy. Power needed for acceleration results in a change of kinetic energy and is therefore affected by congestion; road grade, too, has an impact on potential energy change. Apart from the energies, air and rolling resistances are also modelled. There are two frequently mentioned formulas for VSP in the literature. The first was developed by Jimenez and is based directly on changes of energy, and further derived to include drag and rolling resistance coefficients and accelerations [19]. Another formula was developed by Zhai; this also introduces several coefficients [20]. The main difference between the two is that Jimenez uses wind velocity as an independent variable, which is the reason this formula is preferred; in case of unidirectional tunnels the air velocity is usually in the direction of travel, which results in lower air resistance as opposed to the open road.

The downside of the VSP model is that it does not account for engine idling, which can be significant in case of congested traffic. According to [21] and [22], fuel consumption during engine idling is between 0.5 and $1.5 \mathrm{l} / \mathrm{h}$ for light vehicles and a bit over $3 \mathrm{l} / \mathrm{h}$ for heavy vehicles. The VSP is also suitable for adaptation to analysis of alternative drivetrains as it is based on energy consumption with a clear physical background. It is not a regressive model of fuel use. It merely estimates power at the wheels. The power at the engine should be higher 
as transmission and engine efficiencies should be considered as well. A relationship between the vehicle specific power and fuel consumption rate (flow) was conducted by [23, 24].

An exhaustive study involving vehicle efficiency defines separate ratios for powertrain, vehicle and primary energy efficiency [25]. It can be deduced that due to many different fuels that are being used, it is more feasible to have a model that is based on energy and then to calculate primary energy use from the energy at the wheels.

\section{Extraurban case study - Karawanks tunnel}

An analysis of the Karawanks road tunnel connecting northern Slovenia with southern Austria was carried out. It is a single tube tunnel with bidirectional traffic connecting motorways on both sides of the border. It is located under the Karawanks mountain ridge, which is approximately $2500 \mathrm{~m}$ high. This particular route is interesting as all alternative routes are much longer and include many serpentine segments and changes in elevation (as can be seen in figures 3 and 4). In figure 4 the axis represents the geographical longitude and latitude. The road coordinates were obtained from OpenStreetMap, while the elevation data are from GMTED 2010 database [26]. It is evident that the tunnel route (black) is a lot shorter than the alternative route because it crosses the mountain ridge (the white route in figure 4). It is, however, still longer than the hypothetical ideal route (dashed line). Length and elevation comparison of the routes are shown in table 1.

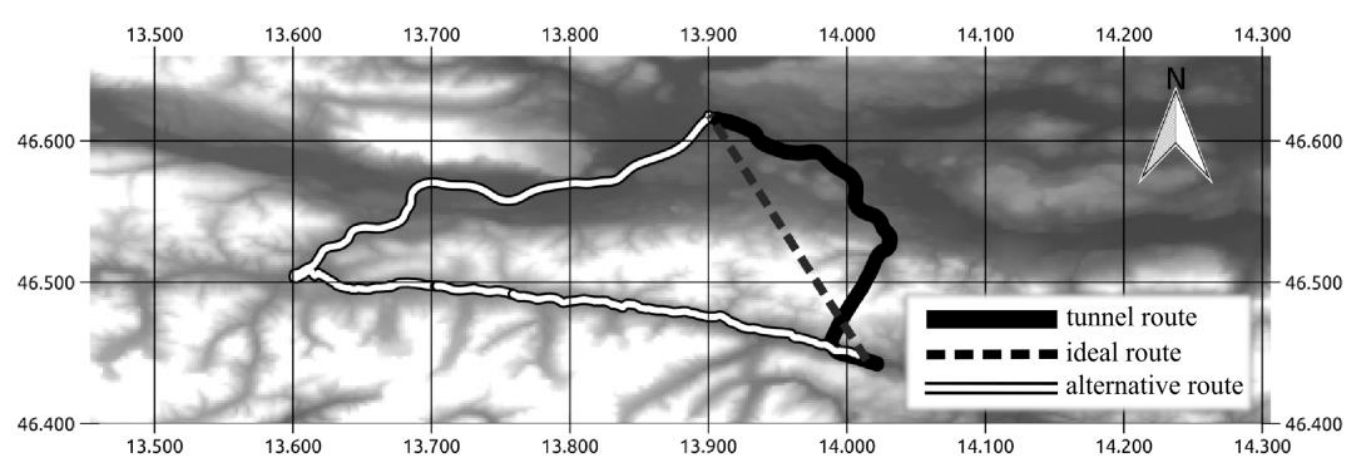

Fig. 3. Tunnel, alternative and ideal routes.

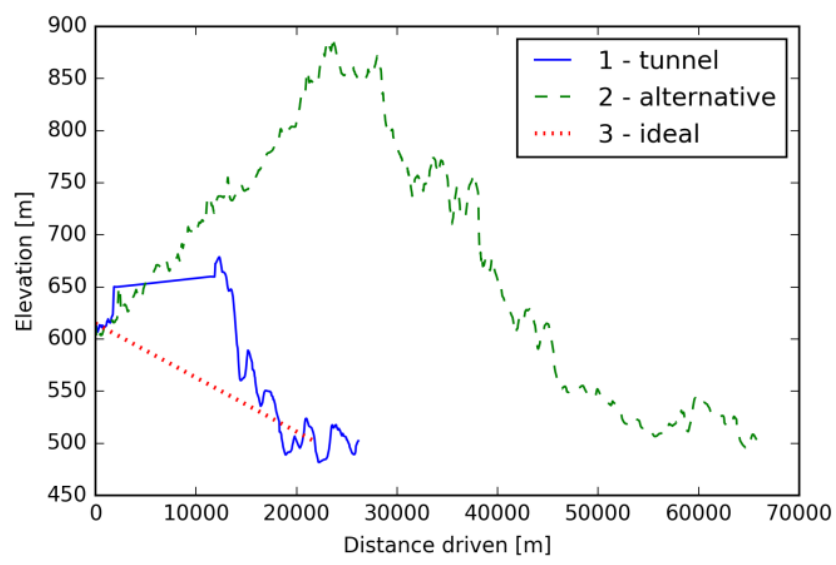

Fig. 4. Elevation profile of the routes. 
Table 1. Basic route characteristics.

\begin{tabular}{|c|c|c|c|}
\hline & Tunnel Route & $\begin{array}{c}\text { Alternative } \\
\text { Route }\end{array}$ & $\begin{array}{c}\text { Ideal } \\
\text { Route }\end{array}$ \\
\hline $\begin{array}{c}\text { Minimum } \\
\text { Elevation }\end{array}$ & $481 \mathrm{~m}$ & $495 \mathrm{~m}$ & $510 \mathrm{~m}$ \\
\hline $\begin{array}{c}\text { Maximum } \\
\text { Elevation }\end{array}$ & $679 \mathrm{~m}$ & $890 \mathrm{~m}$ & $622 \mathrm{~m}$ \\
\hline Route Length & $26.2 \mathrm{~km}$ & $66.2 \mathrm{~km}$ & $21.7 \mathrm{~km}$ \\
\hline Tunnels & $8019 \mathrm{~m}$ & - & - \\
\hline
\end{tabular}

It would be possible to split traffic data into several time periods, but since detailed traffic data were not available analysis using an average number of vehicles per day was conducted: separating them into personal vehicles, busses, light commercial vehicles and heavy goods vehicles. Vehicle weight for each class was approximated. An overview of traffic data can be seen in the table 2 . As can be seen, the traffic volume is relatively low with a high share of personal vehicles.

After obtaining the traffic data, we assigned each vehicle class an approximate weight and length. The vehicle length is needed for microsimulation as well.

Table 2. Traffic data.

\begin{tabular}{|c|c|c|c|}
\hline & Daily traffic & Approximate weight [t] & $\begin{array}{c}\text { Vehicle } \\
\text { length [m] }\end{array}$ \\
\hline Personal vehicles & 7144 & 1.5 & 5 \\
\hline Busses & 96 & 20 & 11 \\
\hline Light goods vehicles (up to 7t) & 884 & 4 & 7 \\
\hline Heavy goods vehicles (over 7t) & 1164 & 40 & 12 \\
\hline
\end{tabular}

After obtaining vehicle trajectories, VSP calculation along the route was carried out. The VSP is highly dependent on road grade and accelerations. Changes in road grade have many peaks that are not evident in reality because of the resolution of satellite elevation data and the very steep changes in elevation in these narrow Alpine valleys. These peaks will not necessarily yield wrong results as there are significant changes in elevation on the actual road which are spread over longer distances compared to those of the satellite based elevation data. If the analysed road was on a flat area there such irregularities would be minimized.

Calculated average values for energy consumption that were obtained by pre-processing microsimulation vehicle trajectories of each vehicle in a class are shown in table 4 , where route 1 is the tunnel route, 2 is the alternative route and 3 is the ideal route.

Table 3. Mean energy consumption per trip for each vehicle class in $\mathrm{MJ} / \mathrm{t}$.

\begin{tabular}{|c|c|c|c|}
\hline Route & $\mathbf{1}$ & $\mathbf{2}$ & $\mathbf{3}$ \\
\hline Personal vehicles & 14.5 & 39.3 & 13.3 \\
\hline Busses & 13.6 & 37.4 & 12.5 \\
\hline Light goods vehicles (up to 7t) & 13.6 & 37.4 & 12.5 \\
\hline Heavy goods vehicles (over 7t) & 13.1 & 36.3 & 11.3 \\
\hline
\end{tabular}

Based on data from table 4 the daily amount of energy consumed by all vehicles on all 3 routes can be calculated according to the eq. 7 . The results can be seen in table 6 , which shows that the tunnel route is about 3 times more efficient than the alternative route $(230 \%$ more energy is consumed). An interesting overview is the average daily power needed to drive all the vehicles that pass on the route for all three options. The difference between the 
tunnel and alternative routes is $18 \mathrm{MW}$ which is an order of magnitude of a smaller electrical power station. This means that the impact of road geometry on fuel consumption is far from negligible. I

Table 4. Total energy consumption per route.

\begin{tabular}{|c|c|c|c|}
\hline Route & $\mathbf{1}$ & $\mathbf{2}$ & $\mathbf{3}$ \\
\hline Total Energy[GJ] & 893 & 2431 & 736 \\
\hline Increase over ideal road [\%] & 21 & 230 & 0 \\
\hline P [MW] & 10.3 & 28.13 & 8.5 \\
\hline
\end{tabular}

\section{Urban case study - Celovska street, Ljubljana}

Celovska street is one of major streets in the city of Ljubljana that connects northern bypass ring motorway with city centre. Most of the street has 2 lanes per direction and includes several semaphored intersections. Hourly traffic volume values were obtained from city authorities and are based on inductive loop counters on the street [27]. Average monthly hourly traffic volume from bypass towards the centre can be seen in figures 4 and 5 .

A simulation was carried out using predefined flow of moderate 400 vehicles per hour which is normal daily traffic (excluding peaks) plus random trips across the network. 3 different traffic light control programmes were evaluated among which are: 1 - fixed 90 second cycle programme for all traffic lights, 2 - adaptive programme with extensions of priority phases and maximum allowed cycle duration of $125 \mathrm{~s}$ and 2 - an adaptive programme with phase extensions combined with forced phase switching and synchronisation among junctions. Goal of this simulation is to assess impact of energy consumption on different traffic light management programmes. It is evident that according to the model, there are dramatic differences between noncongested traffic (programmes 2 and 3) and congested (programme 1).

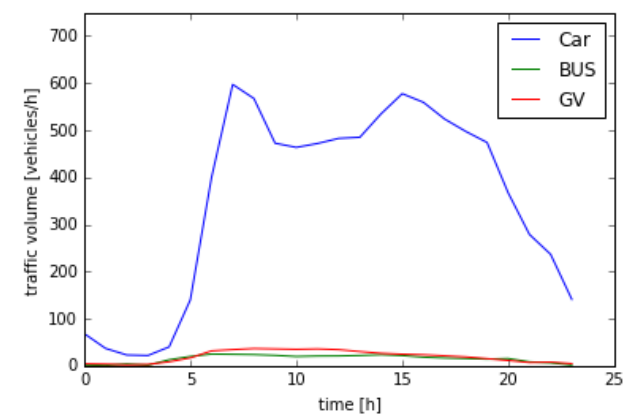

Fig. 4. Hourly traffic, weekdays.

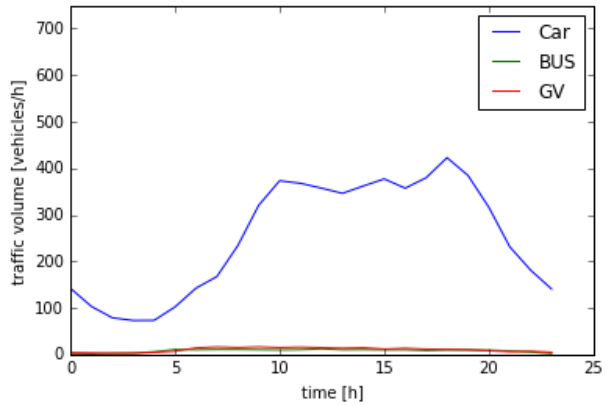

Fig. 5. Hourly traffic, weekends.

Table 5. Total hourly consumption per traffic regime.

\begin{tabular}{|c|c|c|c|}
\hline Route & $\mathbf{1}$ & $\mathbf{2}$ & $\mathbf{3}$ \\
\hline Total Energy[GJ] & 22.9 & 9.7 & 7.4 \\
\hline Average trip duration [s] & 2075 & 665 & 365 \\
\hline P [MW] & 6.4 & 2.7 & 2.0 \\
\hline
\end{tabular}

To summarize, avoiding congested stop and go traffic can significantly reduce energy consumption of the motor vehicles and it can be achieved by optimization of traffic light 
control programmes. These results are still preliminary as more detailed traffic data are needed. It should be noted that modelled traffic control programmes are not currently used programmes but are an evaluation of different possible traffic control programmes on a realistic traffic network with real traffic volume.

\section{Conclusions}

A methodology to evaluate an impact of road network configuration on energy consumed by the vehicles using the vehicle specific power model presented. It has been shown that it is possible to save enormous amounts of energy by making road networks more energy efficient, by building more direct, shorter routes without significant changes in road grade or by controlling traffic lights more efficiently. First is especially evident in mountainous areas where open roads must pass through significant variations in elevation. This results in longer routes with higher road grades, causing higher energy consumption. In the cities same effect was observed by avoiding congestions with more efficient control of traffic lights.

Vehicle energy consumption was modelled with an assumption that no braking energy is recovered. In order to simulate electric and plug-in hybrid vehicles, simple modifications to the VSP model are needed.

\section{References}

1. E. Commissie, White paper, Roadmap to a single European Transport Area, Towards a competitive and resource efficient transport system. COM (2011)

2. Statistical Office of the European Communities, Smarter, greener, more inclusive?: indicators to support the Europe 2020 strategy. Luxembourg: Publications Office of the European Union, (2015)

3. "ODYSSEE - MURE 2012. Trends and policies for energy savings and emissions in transport." (Jul-2015)

4. P. ten Brink, New Clim. Policies Eur. Union Intern. Legis. Clim. Dipl. 15, 179 (2010)

5. A. Gambhir, L. K. C. Tse, D. Tong, and R. Martinez-Botas, Appl. Energy 157, 905-917 (2015)

6. N. Bianco and F. Litz, "Reducing greenhouse gas emissions in the United States using existing federal authorities and state action," The World Resources Institute, $10 \mathrm{G}$ Street, NE Suite 800 Washington, D. C. 20002 USA, (2010)

7. D. Metz, Case Stud. Transp. Policy (2015)

8. K. Ahn, H. Rakha, A. Trani, M. Van Aerde, J. Transp. Eng. 128, 2, 182-190 (2002)

9. A. Sjödin, M. Jerksjö, Evaluation of European road transport emission models against on-road emission data as measured by optical remote sensing (2008)

10. R. Joumard, M. Rapone, M. Andre, and others (2006)

11. M. André, M. Keller, \AAke Sjödin, M. Gadrat, I. M. Crae, The ARTEMIS European tools for estimating the pollutant emissions from road transport and their application in Sweden and France. na (2008)

12. O. Franzese, D. Davidson, Oak Ridge Natl. Lab. Tenn. USA (2011)

13. A. Sadri, M. M. Ardehali, K. Amirnekooei, Energy 77, 831-843 (2014)

14. R. Smit, R. Smokers, E. Rabé, Transp. Res. Part Transp. Environ. 12, 6, 414-422 (2007)

15. P. Hidas, Road Transp. Res. 14, 4 (2005) 
16. M. Behrisch, L. Bieker, J. Erdmann, and D. Krajzewicz, "Sumo-simulation of urban mobility," in The Third International Conference on Advances in System Simulation (SIMUL 2011), Barcelona, Spain, Third Int. Conf. Adv. Syst. Simul. SIMUL 2011 Barc. Spain, (2011)

17. D. Krajzewicz, M. Behrisch, P. Wagner, R. Luz, M. Krumnow, in Modeling Mobility with Open Data, Springer, 203-221 (2015)

18. D. Krajzewicz, J. Erdmann, M. Behrisch, L. Bieker, Int. J. Adv. Syst. Meas. 5, 3\&4, (2012)

19. J.L. Jimenez-Palacios, "Understanding and quantifying motor vehicle emissions with vehicle specific power and TILDAS remote sensing," Massachusetts Institute of Technology (1998)

20. H. Zhai, H.C. Frey, N.M. Rouphail, Environ. Sci. Technol. 42, 21, 7985-7991 (2008)

21. H.C. Frey, A. Unal, N. M. Rouphail, J.D. Colyar, J. Air Waste Manag. Assoc. 53, 8, 992-1002 (2003)

22. S.M.A. Rahman, H.H. Masjuki, M.A. Kalam, M.J. Abedin, A. Sanjid, S. Imtenan, J. Clean. Prod. 69, 208-215 (2014)

23. G. Song, L. Yu, Transp. Res. Rec. J. Transp. Res. Board 2139, 11-20 (2009)

24. G. Song, L. Yu, Transp. Res. Rec. J. Transp. Res. Board 2233, 90-98 (2011)

25. M. Åhman, Energy 26, 11, 973-989 (2001)

26. J.J. Danielson, D.B. Gesch, "Global multi-resolution terrain elevation data 2010 (GMTED2010),” US Geological Survey (2011)

27. "Traffic counting data from Celovska street.” JP LPT Ljubljana (2016) 